\title{
Extreme dependence of Chloroflexus aggregans LOV domain thermo- and photostability on the bound flavin species
}

\author{
Anastasia Smolentseva ${ }^{1} \cdot$ Ivan M. Goncharov ${ }^{1} \cdot$ Anna Yudenko $^{1} \cdot$ Andrey Bogorodskiy $^{1} \cdot$ Oleg Semenov $^{1}$. \\ Vera V. Nazarenko' ${ }^{1}$ Valentin Borshchevskiy ${ }^{1,6}$ - Alexander V. Fonin ${ }^{2} \cdot$ Alina Remeeva $^{1} \cdot$ Karl-Erich Jaeger $^{3,4}$. \\ Ulrich Krauss $^{3,4} \cdot$ Valentin Gordeliy ${ }^{1,5,6} \cdot$ Ivan Gushchin $^{1}$ (1)
}

Received: 6 September 2021 / Accepted: 8 November 2021 / Published online: 18 November 2021

(c) The Author(s), under exclusive licence to European Photochemistry Association, European Society for Photobiology 2021

\begin{abstract}
Light-oxygen-voltage (LOV) domains are common photosensory modules that found many applications in fluorescence microscopy and optogenetics. Here, we show that the Chloroflexus aggregans LOV domain can bind different flavin species (lumichrome, LC; riboflavin, RF; flavin mononucleotide, FMN; flavin adenine dinucleotide, FAD) during heterologous expression and that its physicochemical properties depend strongly on the nature of the bound flavin. We show that whereas the dissociation constants for different chromophores are similar, the melting temperature of the protein reconstituted with single flavin species varies from $\sim 60^{\circ} \mathrm{C}$ for LC to $\sim 81^{\circ} \mathrm{C}$ for FMN, and photobleaching half-times vary almost 100 -fold. These observations serve as a caution for future studies of LOV domains in non-native conditions yet raise the possibility of fine-tuning various properties of LOV-based fluorescent probes and optogenetic tools by manipulating the chromophore composition.
\end{abstract}

\section{Graphical abstract}
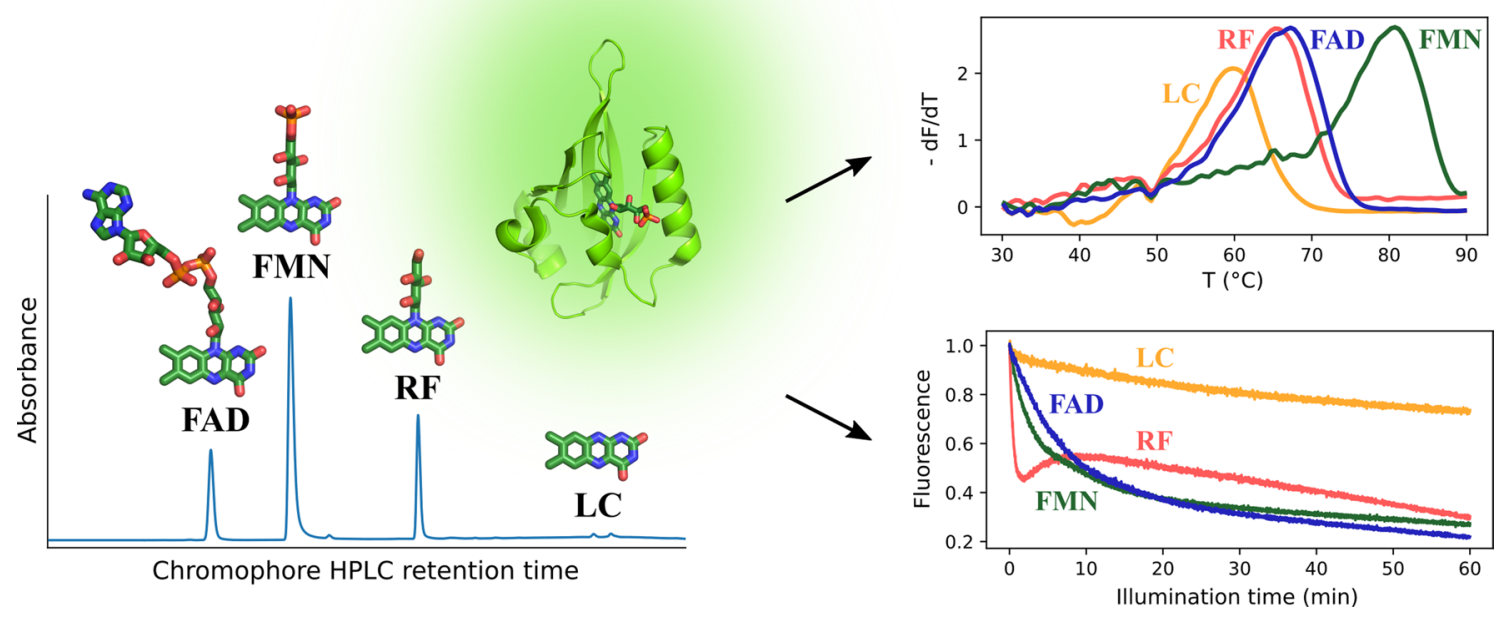

Keywords LOV domain · Flavin-based fluorescent protein · Riboflavin · Flavin mononucleotide $\cdot$ Chromophore $\cdot$ Thermal stability $\cdot$ Protein-ligand interactions

Ivan Gushchin

ivan.gushchin@phystech.edu

Extended author information available on the last page of the article 


$\begin{array}{ll}\text { Abbreviations } \\ \text { CFP } & \text { Cyan fluorescent protein } \\ \text { FAD } & \text { Flavin adenine dinucleotide } \\ \text { FbFP } & \text { Flavin-based fluorescent protein } \\ \text { FMN } & \text { Flavin mononucleotide } \\ \text { GFP } & \text { Green fluorescent protein } \\ \text { HPLC } & \text { High-performance liquid chromatography } \\ \text { IPTG } & \text { Isopropyl } \beta \text {-D-1-thiogalactopyranoside } \\ \text { LC } & \text { Lumichrome } \\ \text { LOV } & \text { Light-oxygen-voltage } \\ \text { PAS } & \text { Per-Arnt-Sim } \\ \text { RF } & \text { Riboflavin } \\ \text { RFP } & \text { Red fluorescent protein } \\ \text { SEC } & \text { Size-exclusion chromatography } \\ \text { YFP } & \text { Yellow fluorescent protein }\end{array}$

\section{Introduction}

Light-oxygen-voltage (LOV) domains are ubiquitous photosensory modules found in photoreceptor proteins from all three domains of life [1,2]. They sense blue light and regulate diverse physiological processes such as circadian rhythms [3], phototropism [4, 5], virulence [6] and stress responses [7]. LOV domains are members of the PAS (PerArnt-Sim) superfamily and share the common globular alpha/beta fold [8]. In the core, LOV proteins may bind different flavin chromophores (riboflavin, RF; flavin mononucleotide, FMN; flavin adenine dinucleotide, FAD) with dissociation constants around $0.1-0.9 \mu \mathrm{M}[9,10]$. These flavins are present in all living organisms, and consequently, heterologous expression of LOV domains usually does not require flavin supplementation or genetic introduction of their biosynthesis pathways. Different LOV proteins were also shown to bind modified flavins, such as lumichrome (LC), roseoflavin, 1- or 5-deaza FMN, bromo-, chloro- and fluoro-substituted FMN, and others, in vivo or after renaturation [11-18]. This resulted in shifts of the absorption maxima from $-45 \mathrm{~nm}$ to $+92 \mathrm{~nm}$ and variation of other optical and photophysical properties [11-18].

LOV domains have found many applications in optogenetics, allowing e.g. for the control of protein interactions and protein localization by light $[19,20]$. Due to their photophysical properties, they are also used for design of fluorescent reporters [21-24]. Unlike reporters based on the green fluorescent protein (GFP) and GFP-related $\beta$-barrel proteins such as YFP, CFP or RFP, LOV domains do not require oxygen for chromophore maturation [21, 25]. Therefore, they can be used for studying low oxygen phenomena such as cerebral ischemia, tumor hypoxia, pathogenesis, and biofilm development.

Thermal stability is one of the most important properties of fluorescent reporters, as it may increase the resistance of the protein against proteolysis [26, 27], expands its usability in extreme conditions and often allows for easier engineering of modified variants [28]. Previously, genome mining approaches were used to discover naturally occurring thermostable proteins [29], including CagFbFP, based on the LOV domain from a putative sensory histidine kinase of the thermophilic bacterium Chloroflexus aggregans [30]. Interestingly, studying its thermal denaturation, we observed two transitions (Fig. 1a), and overall variation of properties from batch to batch. Moreover, it was not clear whether the two melting transitions were consecutive, observed for all protein molecules in the sample, or represented different fractions of the protein samples. In addition, thermal stability measurements of several variants of $\mathrm{CagFbFP}$ also revealed two melting temperatures. In prolinesubstituted $\mathrm{CagFbFP}$ variants, the temperature of both transitions is raised by up to $\sim 2^{\circ} \mathrm{C}$ [31]. In the variants generated to achieve spectral tuning, both transitions are shifted to lower temperatures $[32,33]$. Finally, two or even three different transitions were observed in variants with extended flexible loops of different lengths, which were designed for identification of the best potential split sites during the process of generating a split flavin-based fluorescent reported based on $\mathrm{CagFbFP} \mathrm{[34].}$

Another important property of fluorescent proteins is photostability. In solution, illuminated flavins are degraded to LC and lumiflavin derivatives [35]. Similarly, in a LOV1 domain of phototropin from Chlamydomonas reinhardtii complexed with roseoflavin monophosphate, prolonged illumination caused photodegradation of the cofactor to fully reduced flavin and lumichrome derivatives [18]. In a representative FbFP, miniSOG, generation of reactive oxygen species leads to photodegradation of the bound FMN to LC, as well as to modification of protein amino acids [36]. While normally LC is not synthesized by the cells directly, it sometimes can be found in LOV variants after heterologous expression and purification [37].

In this work, we developed a protocol for deflavination of heterologously expressed $\mathrm{CagFbF}$, and reconstituted the resulting apoprotein with RF, FMN, FAD, and LC. We studied physicochemical properties of the resulting holoproteins and found that they depend strongly on the chromophore type. We show that the melting transitions observed in the heterologously expressed samples may be ascribed to protein species bound to different flavins. The results highlight the importance of accurate characterization of heterologously expressed and purified protein samples and suggest that the properties of LOV-based proteins used in optogenetics and fluorescence microscopy may be tuned by altering the chromophore composition. 

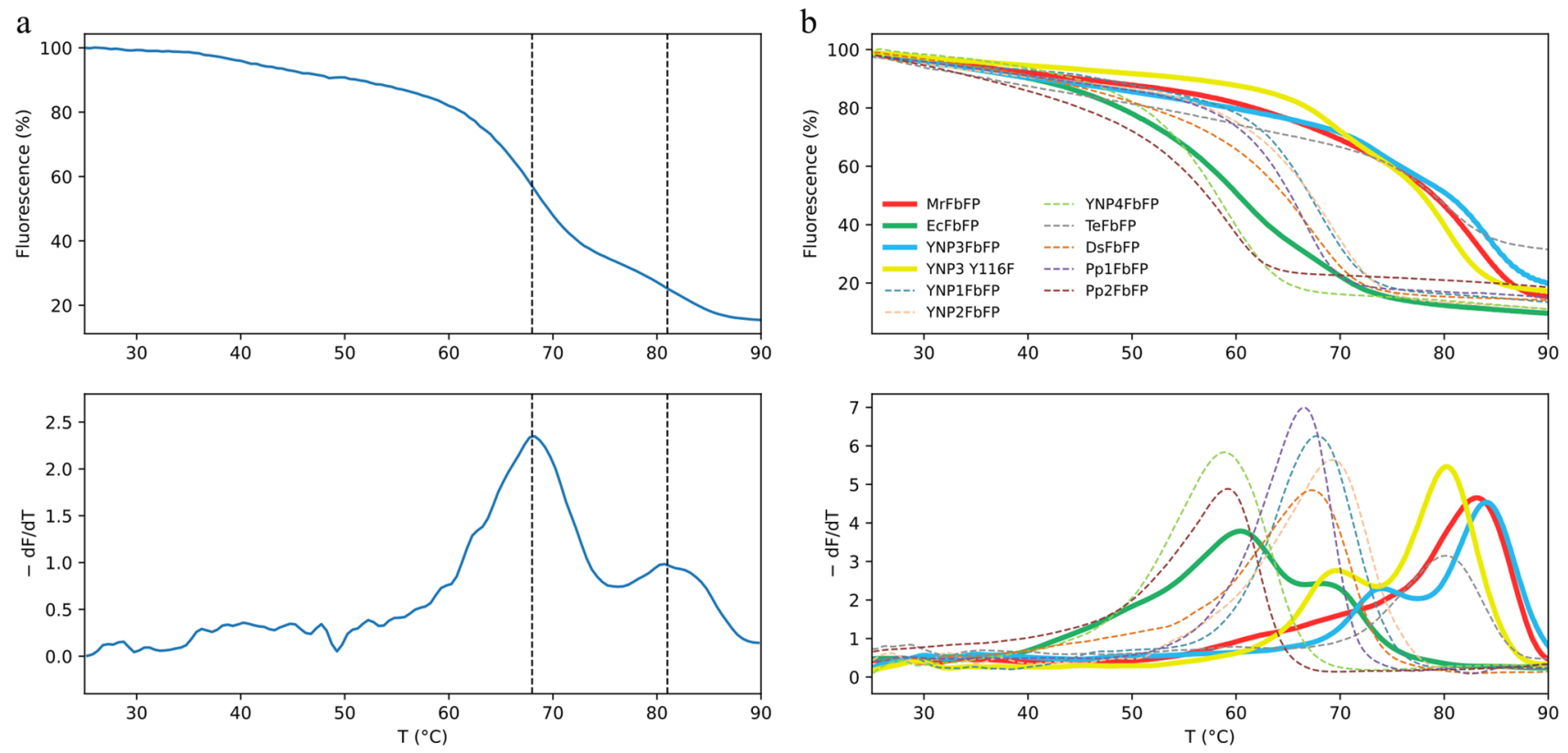

Fig. 1 Thermal stability of $\mathrm{CagFbFP}$ and other FbFPs. a The decrease in the FbFP-specific fluorescence intensity during heating (upper panel) and the first derivative of the data (lower panel). Two transitions are observed. Corresponding melting temperatures (68 and $81{ }^{\circ} \mathrm{C}$ ) are marked with the dashed lines. b Fluorescence melting curves of $E c F b F P$ and a set of FbFPs from thermophilic micro-

\section{Results and discussion}

\subsection{Properties of heterologously expressed LOV domains}

Recently, we have identified and characterized a flavinbinding fluorescent protein $\mathrm{Cag} \mathrm{FbFP}$, derived from the $\mathrm{LOV}$ domain of a putative sensory histidine kinase Cagg_3753 from the thermophilic bacterium $C$. aggregans. During temperature-induced denaturation, the heterologously expressed protein revealed two melting transitions, at $\sim 68$ and $81{ }^{\circ} \mathrm{C}$ (Fig. 1a), the reason for which was not clear. Moreover, reanalysis of the data for other FbFPs, including those from thermophilic organisms [29], shows that some other proteins $(E c \mathrm{FbFP}, M r \mathrm{FbFP}$ and $\mathrm{YNP} 3 \mathrm{FbFP}$, derived from proteins from Escherichia coli, Meiothermus ruber, and Yellowstone National Park Metagenome Project, respectively) also display melting in at least two steps (Fig. 1b). Interestingly, we observed that while $\mathrm{CagFbFP}$ elutes in a single peak during size-exclusion chromatography (SEC), the different fractions taken from this peak have different thermal stability, with the heavier fractions being more thermostable (Fig. 2).

We hypothesized that the two melting transitions might correspond to protein populations bound to different flavin molecules. It is generally assumed that most LOV domains

organisms reported by Wingen et al. in 2017 [29] (upper panel) and the first derivative of the data (lower panel). The proteins are sourced from Meiothermus ruber ( $\mathrm{Mr} \mathrm{FbFP})$, Escherichia coli $(E c \mathrm{FbFP})$, Yellowstone National Park Metagenome Project (YNP FbFPs), Thermosynechococcus elongatus (TeFbFP), Dinoroseobacter shibae (DsFbFP) and Pseudomonas putida ( $\mathrm{Pp} 1 \mathrm{FbFP}$ and $\mathrm{Pp} 2 \mathrm{FbFP}$ )

predominantly bind FMN as a cofactor, whereas others preferentially bind FAD. Yet, heterologously expressed LOV domains sometimes contain a mixture of all naturally occurring flavins (RF, FMN and FAD) [10, 38]. We, therefore, analyzed the chromophore composition of $\mathrm{CagFbFP}$ overexpressed in E. coli using high-performance liquid chromatography (HPLC) (Fig. S1a). We found that with respect to the total flavin content, the majority (44\%) of the protein contained riboflavin, while $29 \%$ and $19 \%$ of CagFbFP bound FMN and FAD, respectively. We also observed the presence of lumichrome (LC), a photodegradation product of flavins (8\%). It is not clear, if and how the cofactor identity could affect SEC elution volume of the respective protein species.

To test whether the physicochemical properties of $\mathrm{CagF}-$ bFP depend on the chromophore, we developed a protocol for production of apo- $\mathrm{CagFbP}$, based on denaturation using guanidinium hydrochloride $(\mathrm{GuHCl})$. The approach is similar to those reported previously $[11,14,15]$, but requires incubation at $70{ }^{\circ} \mathrm{C}$ in a more concentrated $\mathrm{GuHCl}$ solution for complete removal of the chromophores because of higher stability of $\mathrm{CagFbFP}$. After denaturation and removal of the released flavins, the refolded apo-protein was reconstituted with the natural flavins (FMN, RF, FAD) or with LC (Fig. 3a, b) as described in the Methods section. The flavin load of the resulting $\mathrm{CagFbFP}$ samples was estimated to be 


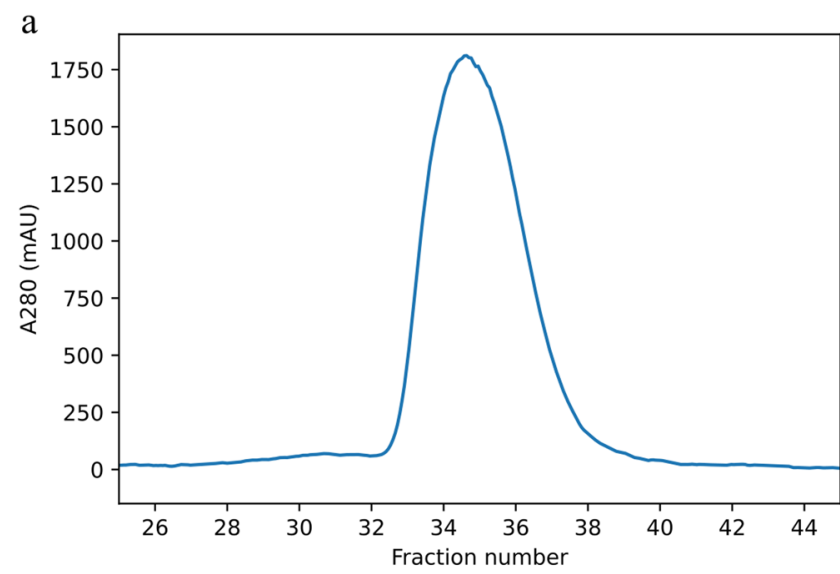

Fig. 2 Dependence of the thermal stability of size-exclusion chromatography (SEC)-purified $\mathrm{CagFbFP}$ on fraction number. a SEC profile of $\mathrm{CagFbFP}$ purified using Superdex ${ }^{\circledR} 200$ Increase 10/300 GL col-

65-75\% as described in the Methods section. Chromophore composition of each sample was verified by HPLC (Fig. S1b-e).

\subsection{Thermal stability}

We first determined the thermal stability of $\mathrm{CagFbFP}$ reconstituted with different chromophores by measuring the flavin fluorescence using spectrofluorimetry and the fluorescence of aromatic amino acids by nano-differential scanning fluorimetry (nanoDSF) (Fig. 3c, d). When heated, the protein denatures and releases the flavin cofactor. This results in a decrease of fluorescence emission with the maximum at $495 \mathrm{~nm}$, characteristic for most protein-bound flavins. When CagFbFP contained exclusively one type of cofactor, all flavin fluorescence-based melting measurements revealed a single transition (Fig. 3c). Proteins containing FMN exhibited the highest thermal stability $\left(T_{\mathrm{FMN}}=81{ }^{\circ} \mathrm{C}\right)$, which is 14-15 degrees higher than that of the proteins containing RF or FAD $\left(T_{\mathrm{RF}}=66^{\circ} \mathrm{C}, \mathrm{T}_{\mathrm{FAD}}=67^{\circ} \mathrm{C}\right)$. The least thermostable is $\mathrm{CagFbFP}$ containing $\mathrm{LC}\left(T_{\mathrm{LC}}=60^{\circ} \mathrm{C}\right)$.

When bound to a LOV domain, the flavin molecule quenches the fluorescence of the nearby aromatic amino acids. Therefore, release of flavin during protein unfolding results in an increase of fluorescence intensity at $330 \mathrm{~nm}$. NanoDSF-based experiments revealed similar melting transitions for $\mathrm{CagFbFP}$ reconstituted with different flavins (Fig. $3 \mathrm{~d}, T_{\mathrm{FMN}}=81.7^{\circ} \mathrm{C}, T_{\mathrm{RF}}=70.1^{\circ} \mathrm{C}, T_{\mathrm{FAD}}=71.0^{\circ} \mathrm{C}$, $T_{\mathrm{LC}}=61.5^{\circ} \mathrm{C}$ ). Thus, we conclude that FMN-bound $\mathrm{CagF}$ bFP is more thermostable than the Bacillus subtilis YtvALOV domain engineered for thermostability [39] and comparable to engineered iLOV [40] and the most thermostable LOV domains from other microorganisms [29] (Fig. 1b).

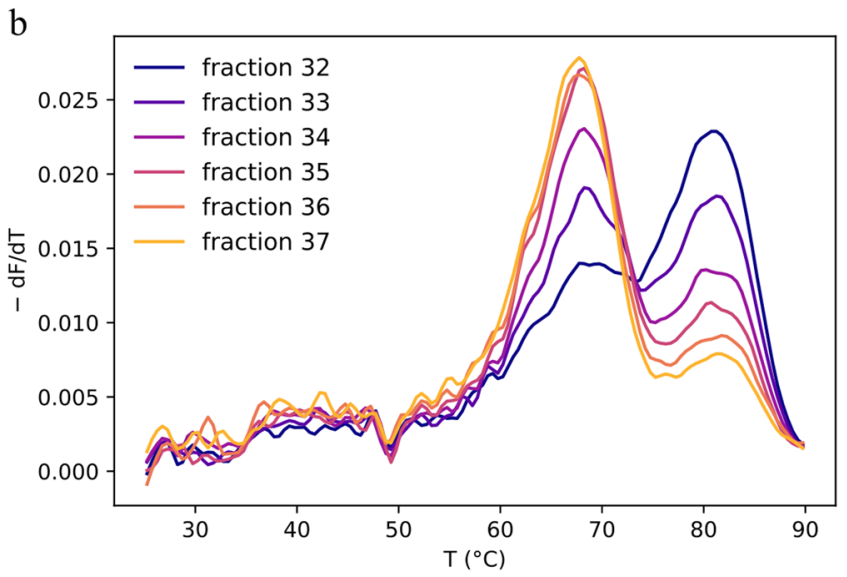

umn. Fraction volume is $0.5 \mathrm{ml}$. b First derivative of the FbFP-specific fluorescence as a function of temperature for different $\mathrm{CagFbFP}$ SEC fractions (normalized to have equal area under curve)

Moreover, the two transitions observed for the heterologously expressed $\mathrm{CagFbFP}$ may be explained by binding of different chromophores during heterologous expression. Increased stability in the series LC-RF-FMN (Fig. 3a) may be explained by increasing favorable stabilizing interactions. The LC moiety is hydrogen-bonded to $\mathrm{Gln} 89$, Asn117, Asn 127 and Gln148; the ribityl moiety is additionally bonded to Asn84 and Gln89; the phosphate group is coordinated by Arg86 and Arg102 (Fig. 3b). Yet, decreased stability of the FAD-bound protein is surprising, since FAD contains all of the atoms of FMN, may interact with the protein similarly, and there are no evident unfavorable interactions (Fig. 3a, b). Finally, while we cannot be certain that the previously studied LOV proteins, displaying two-step melting ( $E c$ FbFP, $M r F b F P$ and YNP3FbFP, Fig. 1 b), also bind different flavins, we note that the temperature difference between their two melting steps is also around $10{ }^{\circ} \mathrm{C}$. We also note that the bacterium $C$. aggregans, from which $\mathrm{CagFbFP}$ was derived, was found in bacterial mats with cyanobacteria in freshwater of hot springs with a temperature of $50-67^{\circ} \mathrm{C}$ [41]. Thus, in natural conditions in vivo, the protein might be binding preferentially FMN, since it would be frequently unfolded when bound to other flavin species, assuming similar melting behavior in an in vivo environment.

We next tested dependence of the melting temperature of $\mathrm{CagFbFP}$ reconstituted with different flavins on the buffer $\mathrm{pH}$ value (Fig. 4). We found that the FMN-bound protein is the most stable in the $\mathrm{pH}$ range $7-9$, and the melting temperature is reduced to $\sim 62{ }^{\circ} \mathrm{C}$ at acidic $\mathrm{pH}$. This might be explained by protonation of the phosphate group, which at neutral $\mathrm{pH}$ interacts favorably with the nearby positively charged side chains of arginines 86 and 102. Accordingly, stability of RF- and FAD-bound proteins is less dependent 
a

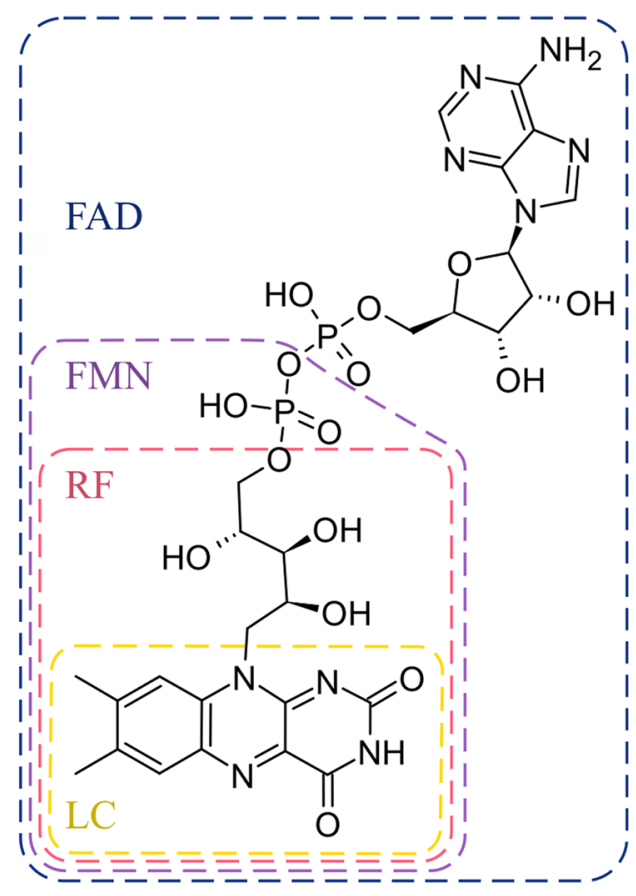

c
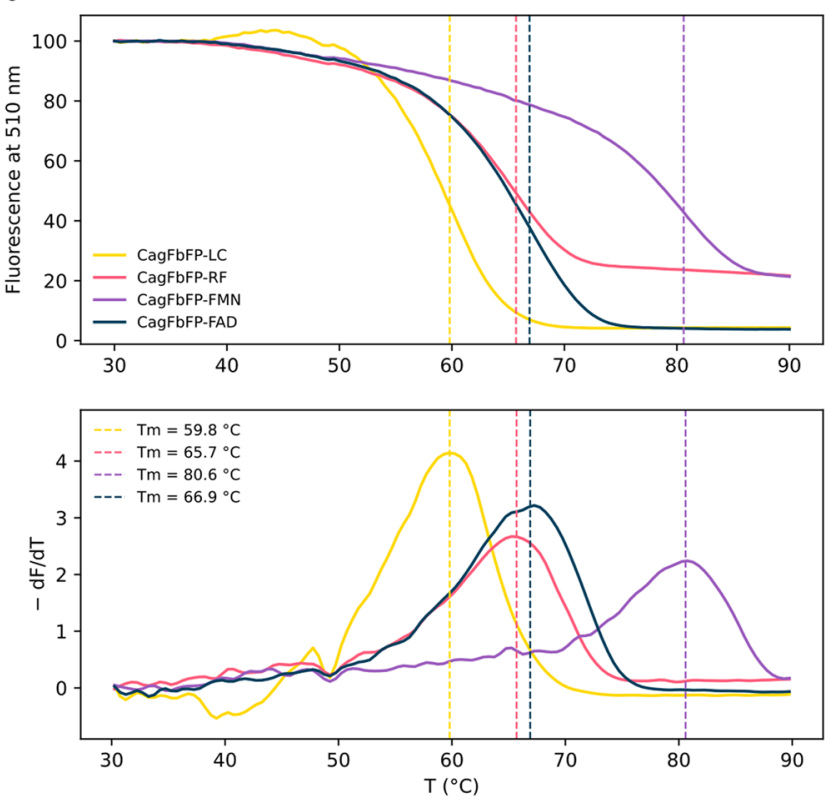

Fig. 3 Thermal stability of $\mathrm{CagFbFP}$ reconstituted with different flavins. a Chemical structures of the flavins used as CagFbFP chromophores in this work: LC (7,8-dimethyl-isoalloxazine tautomer is shown), RF, FMN and FAD. b Protein-chromophore interactions in $\mathrm{CagFbFP}$. Polar and charged amino acids are shown explicitly. The protein model (yellow) is PDB ID 6RHF [30]; the FAD struc-

on $\mathrm{pH}$, since RF lacks the phosphate group, and the pyrophosphate moiety in FAD has higher negative charge. Avena sativa phototropin 1 LOV2 (AsLOV2) was recently found to be stable in a broad $\mathrm{pH}$ range as well [42]. b

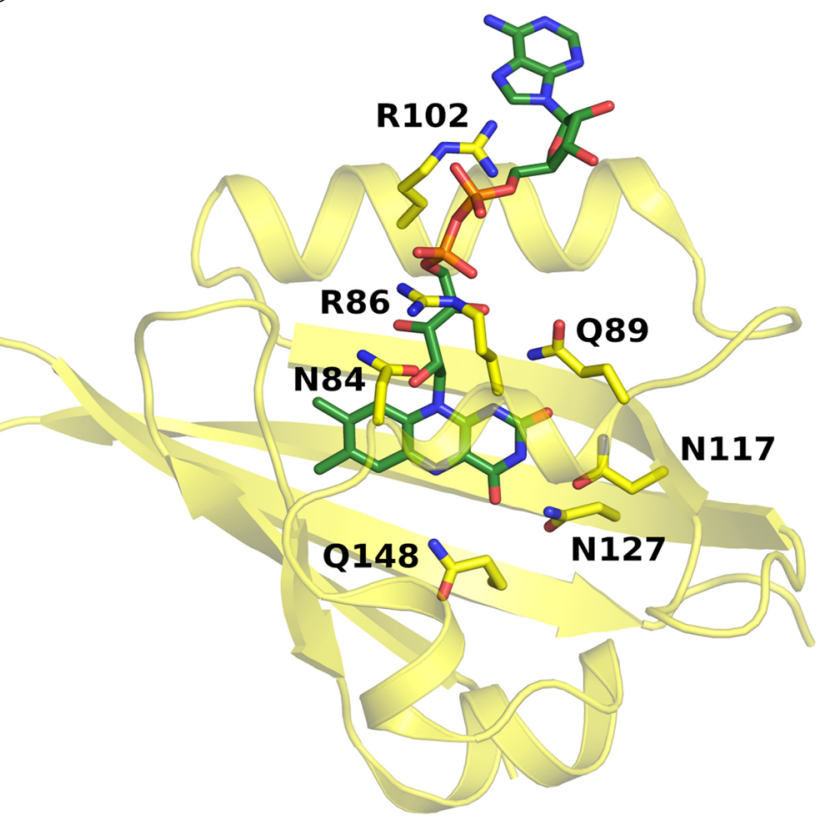

d
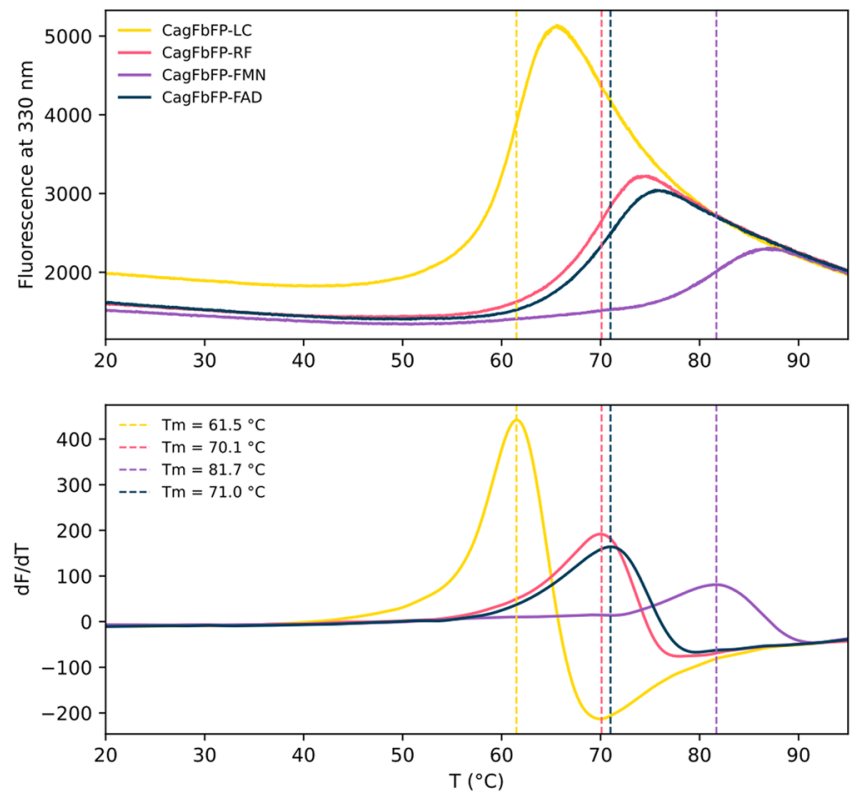

ture (green) is taken from PDB ID 2PD7 [43]. c, d Melting curves of $\mathrm{CagFbFP}$ variants determined based on flavin (c) and aromatic amino acid (d) fluorescence. Upper panels show dependence of the fluorescence intensity on temperature and lower panels show the first derivative of the data. Melting temperatures are marked with dashed lines

\subsection{Photophysical properties}

To further evaluate the photophysical properties of $\mathrm{CagF}$ bFP reconstituted with different chromophores, we measured fluorescence excitation, fluorescence emission and absorption spectra (Fig. 5), as well as fluorescence quantum 


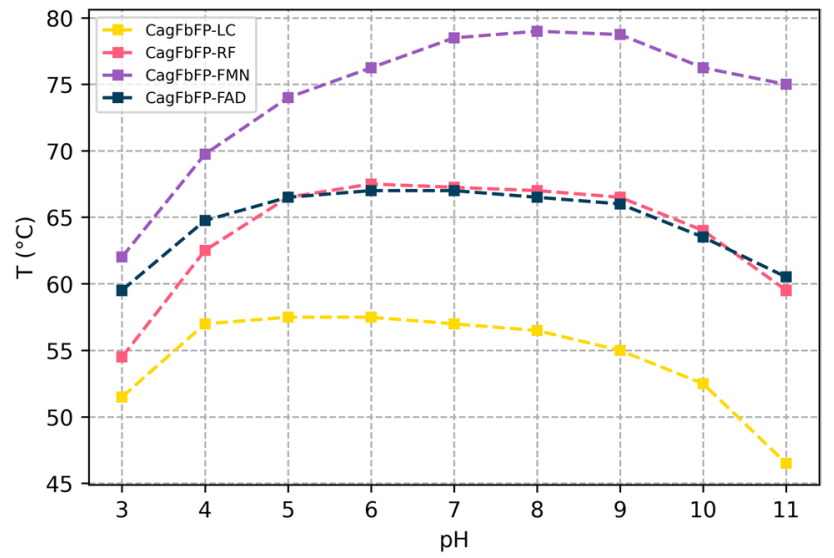

Fig. 4 Dependence of the melting temperature of $\mathrm{CagFbFP}$ reconstituted with different flavins on the buffer $\mathrm{pH}$ value

yield $\left(\Phi_{\mathrm{F}}\right)$ and extinction coefficients of the protein-bound flavin (Table 1). CagFbFP samples containing the natural

a

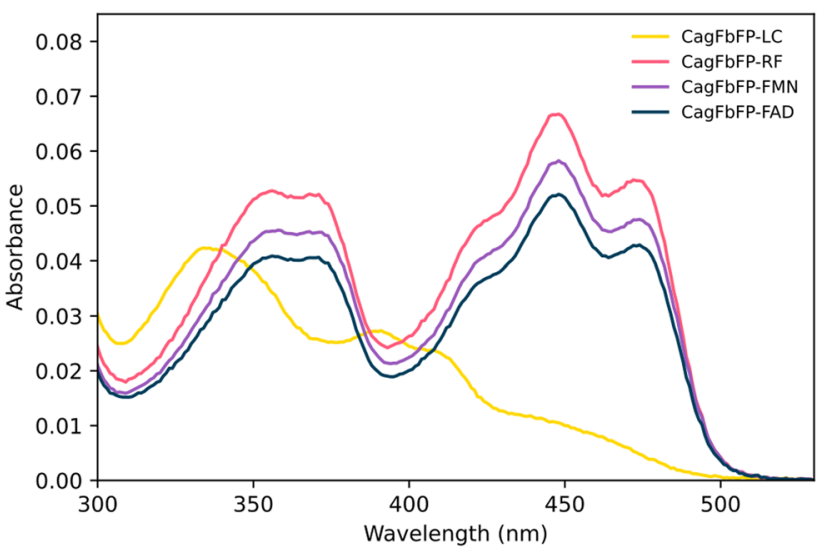

Fig. 5 Absorption and fluorescence spectra of $\mathrm{CagFbFP}$ reconstituted with different flavins. a Absorption spectra of $\mathrm{CagFbFP}$ reconstituted with LC, RF, FMN and FAD. b Fluorescence excitation (solid) and flavins FMN, FAD or RF exhibit similar properties that differ drastically from the protein containing LC. The spectra of $\mathrm{CagFbFP}-\mathrm{LC}$ are similar to those of miniSOG after FMN photodegradation to LC [36]. Fluorescence quantum yield of $\mathrm{CagFbFP}-\mathrm{LC}$ (0.5) is 1.4 times higher compared to that of other samples (0.34-0.36). However, due to its low extinction coefficient, $\mathrm{CagFbFP-LC}$ is almost three times less bright than $\mathrm{CagFbFP}$ loaded with RF/FMN/FAD (when excited at the respective excitation maximum). The results are consistent with findings for the protein W619_1-LOV [11].

Next, we analyzed photostability-the ability of the protein to remain fluorescent under constant illumination (Fig. 6). $\mathrm{CagFbFP-FAD}$ and $\mathrm{CagFbFP-FMN}$ exhibit moderate photostability with photobleaching half-times of 10.1 and $8.6 \mathrm{~min}$, respectively. Decay of $\mathrm{CagFbFP-FMN} \mathrm{fluorescence} \mathrm{is} \mathrm{more}$

b

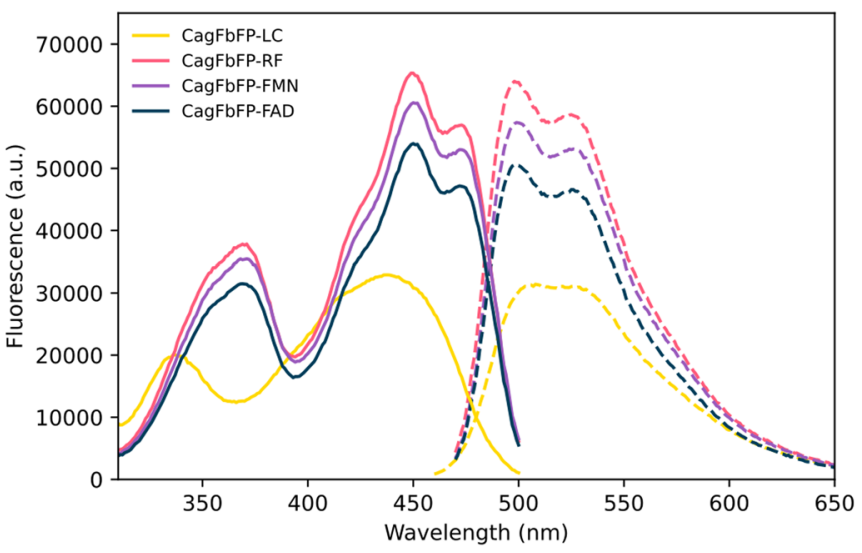

emission (dashed lines) spectra of CagFbFP reconstituted with LC, RF, FMN and FAD

Table 1 Spectral properties and thermal stability of $\mathrm{CagFbFP}$ reconstituted with different flavins

\begin{tabular}{lllll}
\hline & CagFbFP-LC & CagFbFP-RF & CagFbFP-FMN & CagFbFP-FAD \\
\hline Absorbance $\lambda_{\max }(\mathrm{nm})$ & 335,390 & 447 & 447 & 447 \\
Excitation $\lambda_{\max }(\mathrm{nm})$ & 435 & 450 & 450 & 450 \\
Emission $\lambda_{\max }(\mathrm{nm})$ & 508 & 498 & 499 & 498 \\
$\varepsilon\left(\mathrm{M}^{-1} \mathrm{~cm}^{-1}\right)$ & 3937 & 16,444 & 15,812 & 15,401 \\
$\Phi_{\mathrm{F}}$ & 0.50 & 0.36 & 0.34 & 0.34 \\
Brightness $\left(\mathrm{M}^{-1} \mathrm{~cm}^{-1}\right)$ & 1969 & 5920 & 5376 & 5236 \\
$t_{\text {bl, 50\% }}(\min )$ & 240 & $0.9(20.5)$ & 8.6 & 10.1 \\
$T_{\text {Fluor }}\left({ }^{\circ} \mathrm{C}\right)$ & $59.8 \pm 1.9$ & $65.7 \pm 1.9$ & $80.6 \pm 0.8$ & $66.9 \pm 1.4$ \\
$T_{\text {nanoDSF }}\left({ }^{\circ} \mathrm{C}\right)$ & $61.5 \pm 0.1$ & $70.1 \pm 0.2$ & $81.7 \pm 0.2$ & $71.0 \pm 0.1$ \\
\hline
\end{tabular}

Errors associated with the melting temperatures (thermal stability measurements) are expressed as standard deviation derived from three independent measurements 


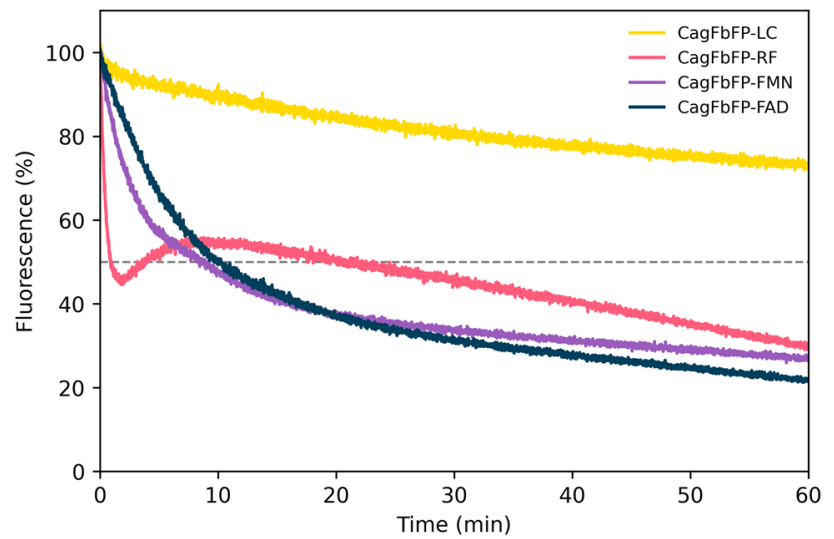

Fig. 6 Photobleaching kinetics of CagFbFP bound to LC, RF, FMN and FAD. Samples were continuously illuminated using a highpower LED. During illumination, fluorescence was excited at $450 \mathrm{~nm}$ (435 nm for CagFbFP-LC) and recorded at $495 \mathrm{~nm}$ (1 data point per second). CagFbFP-LC photobleaching kinetics was recorded for $4 \mathrm{~h}$ (see also Figure S2)

rapid in approximately the first $5 \mathrm{~min}$ and slows down noticeably thereafter. Fluorescence of $\mathrm{CagFbFP}-\mathrm{RF}$ decays with the fastest rate and reaches the half of its initial value within 0.9 min. Unexpectedly, after reaching $45 \%$, the signal from CagFbFP-RF rises back to $55 \%$, before decaying further. Finally, CagFbFP-LC shows an outstanding photostability with photobleaching half-time of $4 \mathrm{~h}$ under the same conditions (Fig. S2). Overall, these results are consistent with the model where the chromophore gets continuously degraded, until it fully converts to lumichrome, which has lower brightness (Table 1) but much higher photostability. Photodegradation of FMN to LC was previously observed for miniSOG [36].

\subsection{Chromophore affinity}

We have also measured the binding properties of different chromophores. Standard incubation experiments of apo$\mathrm{CagFbFP}$ with different concentrations of chromophores were unsuccessful, presumably due to only partial refolding of the protein using our protocol and also due to considerable aggregation of apoprotein during storage and incubation. Consequently, to determine the dissociation constants $\left(\mathrm{K}_{\mathrm{d}}\right)$, we followed the fluorescence of the samples after dilution (Fig. 7) as described in the Methods section.

As expected, $\mathrm{CagFbFP}$ has the highest affinity for FMN $\left(K_{\mathrm{d}}=0.35 \pm 0.02 \mu \mathrm{M}\right)$ and $\mathrm{RF}\left(K_{\mathrm{d}}=0.34 \pm 0.04 \mu \mathrm{M}\right)$, which is approximately two times higher than the affinity for FAD $\left(K_{\mathrm{d}}=0.71 \pm 0.21 \mu \mathrm{M}\right)$. The weakest binding is observed for LC $\left(\mathrm{K}_{\mathrm{d}}=2.3 \pm 0.3 \mu \mathrm{M}\right)$. Lacking the ribityl side chain, LC cannot form as many favorable interactions as other flavins.

Dissociation constants of $\mathrm{CagFbFP}$ for RF, FMN and FAD determined here are similar to the data for other LOV proteins. Dissociation constants of YtvA-LOV from B. subtilis

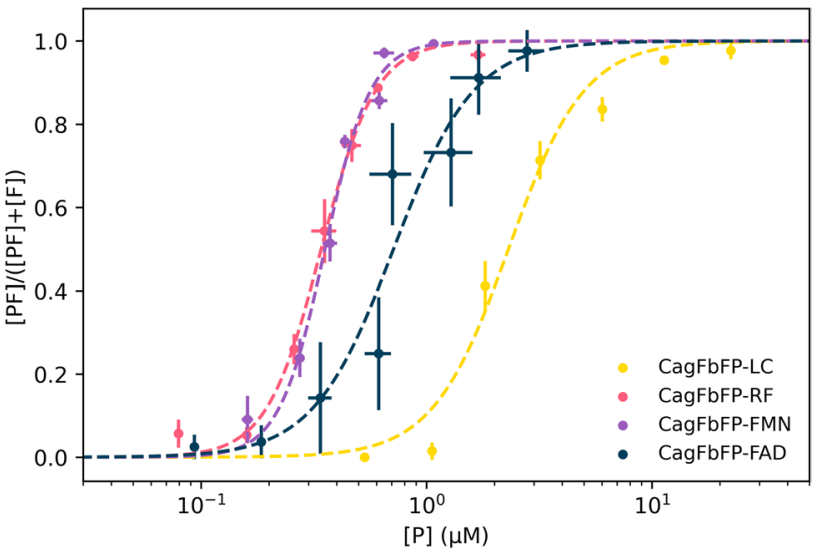

Fig. 7 Determination of $\mathrm{CagFbFP}$ dissociation constants for different flavins. Titration curves are plotted for the fraction of the bound flavins $[\mathrm{PF}] /([\mathrm{PF}]+[\mathrm{F}])$ versus the concentration of the free protein $[\mathrm{P}]$, where $[\mathrm{PF}]$ is the concentration of the protein-flavin complex and $[\mathrm{F}]$ is the concentration of the free flavin. Shown are the means of three independent replicates (six for $\mathrm{CagFbFP}$ reconstituted with FAD), and error bars correspond to the standard deviations

determined using ITC experiments were $K_{\mathrm{d}}=0.351,0.715$ and $0.224 \mu \mathrm{M}$ [10]. Dissociation constants of $E c \mathrm{FbFP}$ (variant of YtvA codon-optimized for $E$. coli) determined using fluorescence titration are $K_{\mathrm{d}}=0.76,0.18$ and $0.13 \mu \mathrm{M}$ and of iLOV (derived from A. thaliana protein) are $K_{\mathrm{d}}=0.89,0.23$ and $0.18 \mu \mathrm{M}$ [9], respectively. We note that some LOV domains, such as Vivid [43] and the LOV domain of WC-1 [44], bind exclusively FAD in their native host. In contrast to $\mathrm{CagFbFP}$, the latter proteins possess an extended loop between the helices $E \alpha$ and $F \alpha$ that interacts with the phosphate and ribose of the adenosine moiety of FAD.

\subsection{Chromophore composition and photostability in vivo}

Different flavins are present naturally in the living cells. Since their LOV domain binding constants are comparable to each other, the chromophore composition of a particular protein may vary depending on different factors (the protein itself, the expression system, the expression conditions). To determine whether the chromophore composition of $\mathrm{CagFbFP}$ is affected by its expression level in E. coli strain C41 (DE3), we conducted a series of experiments where the expression was controlled by a lac promoter (Fig. S3). Then, expression was induced with 0.1 or $100 \mu \mathrm{M}$ of IPTG (Fig. S4) and the protein-bound flavins were analyzed using HPLC (Fig. 8). When expressed at low levels (using $0.1 \mu \mathrm{M}$ IPTG), the protein contains predominantly FMN (67\%), and when it is overexpressed (using $100 \mu \mathrm{M}$ IPTG), more than half of it with respect to the total flavin content contains RF (59\%).

Since the affinities of the protein for FMN and RF are similar, these results suggest that initially the cytoplasmic FMN 
a

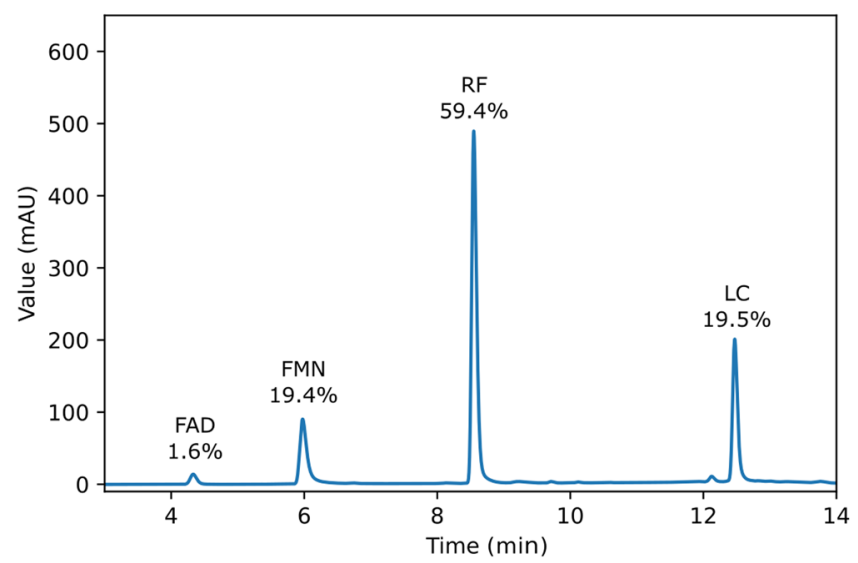

b

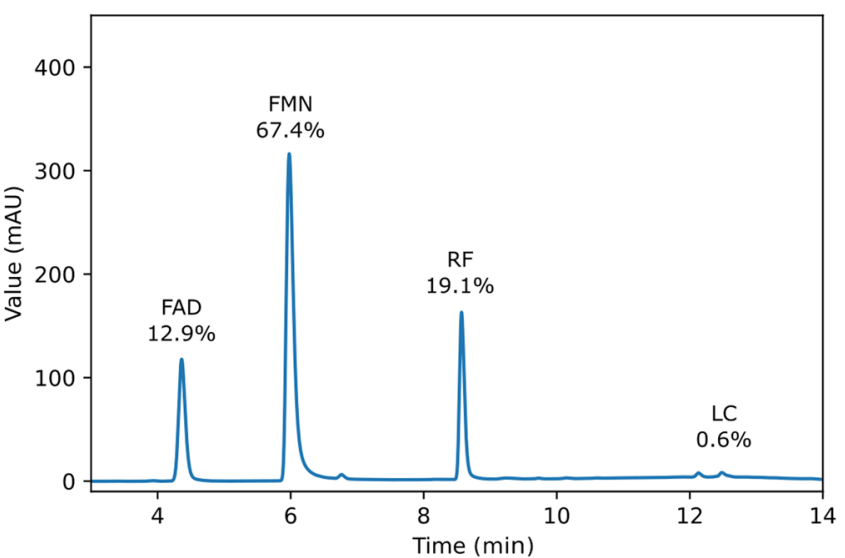

Fig. 8 Chromophore composition of $\mathrm{CagFbFP}$ expressed under different conditions. HPLC elution profiles of flavins extracted from $\mathrm{CagFbFP}$ produced upon high- (a, $0.1 \mathrm{mM}$ IPTG added) and low-level (b, $0.1 \mu \mathrm{M}$ IPTG added) expression. Absorbance was measured at $263 \mathrm{~nm}$

pool exceeds the RF pool. When FMN is depleted, given that FMN is synthesized from RF in E. coli, the protein starts binding more and more RF. Similar to FMN, the amount of proteinbound FAD negatively correlates with the expression level. Given that FAD is synthesized from FMN, this may also be explained by depletion of cellular FMN. Thus, in $E$. coli strain $\mathrm{C} 41$ (DE3), overexpression of $\mathrm{CagFbFP}$ with native flavin profile is limited by the rate of FMN biosynthesis.

Finally, we have analyzed photostability of $\mathrm{CagFbFP}$ in vivo (Fig. 9). Under overexpression conditions, illumination results in strong decay of fluorescence, which then slightly recovers before decreasing further. Under low-level expression conditions, fluorescence decays monotonically and at a slower rate (Fig. 9). These observations are consistent with the findings that overexpressed protein binds more RF than FMN, and RF-bound protein is less photostable compared to FMN-bound protein.

\section{Conclusions}

In this work, we developed a protocol for deflavination of C. aggregans LOV domain-based protein $(\mathrm{CagFbFP})$ and successfully reconstituted it with RF, FMN, FAD and LC. We found that the physicochemical properties of $\mathrm{CagF}$ bFP strongly depend on the nature of the bound flavin. In particular, $\mathrm{Cag}$ FbFP reconstituted with FMN exhibits remarkably high thermal stability, and its melting temperature exceeds the temperature of other variants tested here by $\sim 14{ }^{\circ} \mathrm{C}$ or more. Given that the fluorescence reporter proteins are usually not overexpressed, this hints that the protein may be useful in studies conducted in harsh environments with temperatures reaching $\sim 75^{\circ} \mathrm{C}$. On the other hand, we show that LC-bound protein is extremely

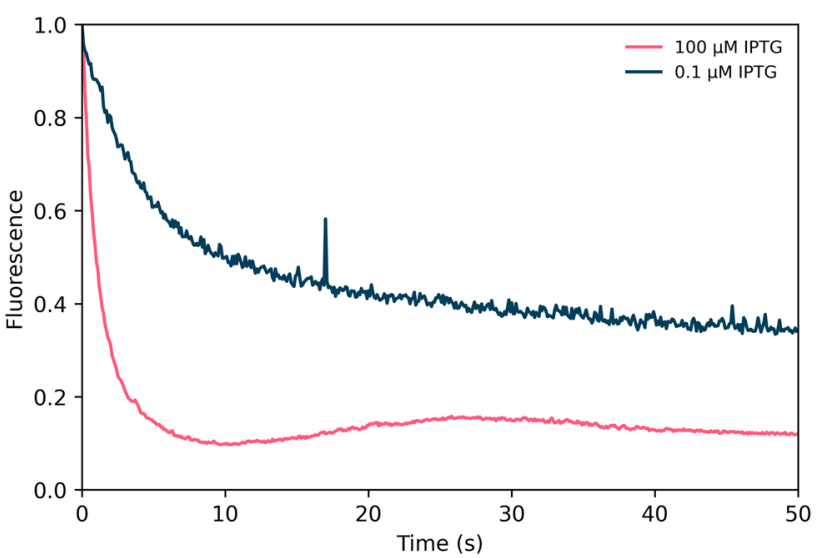

Fig. 9 In vivo photobleaching kinetics of $\mathrm{CagFbFP}$ expressed at different levels in $E$. coli under continuous laser illumination. When expressed at low level (induction using $0.1 \mu \mathrm{M}$ IPTG), CagFbFP predominantly binds FMN and its fluorescence decays monotonously. Under overexpression conditions (induction using $100 \mu \mathrm{M}$ IPTG), $\mathrm{CagFbFP}$ predominantly binds RF and its fluorescence decays more rapidly, displaying complex decay behavior, similar to that of the RFloaded $\mathrm{CagFbFP}$ protein in vitro (Fig. 6). Fluorescence is normalized to the initial pre-photobleaching values. The spike in the $0.1 \mu \mathrm{M}$ IPTG trace at $\sim 18 \mathrm{~s}$ is an artifact

photostable. Because the chromophores have different interactions with the peptide chain, the protein can likely be mutated to alter its flavin-binding preferences, opening the possibility for fine-tuning the optical properties. Finally, our observations serve as a caution for future studies of LOV domains that are overexpressed and purified in non-native conditions, as the determined properties may be different from those observed in applications in vivo. 


\section{Methods}

\subsection{Preparation of apoprotein}

Expression and purification of $\mathrm{CagFbFP}$ were conducted as described previously [30]. Pure protein sample in buffer A (300 mM NaCl, $50 \mathrm{mM}$ Tris-HCl, $\mathrm{pH} 8.0$ ) was added to $8 \mathrm{M}$ $\mathrm{GuHCl}$ in the ratio 1:7. The solution was incubated at $70{ }^{\circ} \mathrm{C}$ for $15 \mathrm{~min}$, then cooled to $40^{\circ} \mathrm{C}$ and diluted to a final concentration of $6 \mathrm{M} \mathrm{GuHCl}$ (in accordance with Ni-NTA Agarose specification). Then, the solution was incubated with Ni-NTA Agarose for $1 \mathrm{~h}$ and loaded onto a gravity flow column. Bound protein was washed with 5 volumes of buffer A supplemented with $6 \mathrm{M} \mathrm{GuHCl}$ to remove the chromophores. The protein was refolded by consecutively washing it with 5 volumes of buffer A supplemented with $4 \mathrm{M}, 2 \mathrm{M}$ or $0 \mathrm{M} \mathrm{GuHCl}$, respectively, and eluted in the apo form with buffer A supplemented with $200 \mathrm{mM}$ imidazole. The removal of bound flavins was determined by the absence of absorbance at $450 \mathrm{~nm}$.

\subsection{Reconstitution of apoprotein with flavins}

Refolded $\mathrm{CagFbFP}$ in apo form was mixed with RF, FMN, FAD or LC in molar ratio 1:3 and incubated for $1 \mathrm{~h}$ at room temperature. Reconstituted protein was concentrated with 10 K MWCO Macrosep ${ }^{\circledR}$ Advance Centrifugal Device. Unbound flavin molecules were removed during buffer exchange to $10 \mathrm{mM} \mathrm{NaCl}, 10 \mathrm{mM}$ sodium phosphate, $\mathrm{pH} 8$ through PD10 columns (GE healthcare, Freiburg, Germany). The flavin load of $\mathrm{CagFbF}$ samples was determined from the absorbance at 450 and $280 \mathrm{~nm}$ as described previously [30].

\subsection{Thermal and pH-stability}

Thermal stability was measured as described previously [34]. $\mathrm{pH}$ dependence of the thermal stability was measured in a series of buffers composed of $10 \mathrm{mM}$ citrate, $10 \mathrm{mM}$ MES, $10 \mathrm{mM}$ HEPES, $10 \mathrm{mM}$ MOPS, $10 \mathrm{mM}$ CHES or $10 \mathrm{mM}$ CAPS with $\mathrm{pH}$ values between 3 and 11 . The $\mathrm{pH}$ of each solution was adjusted by addition of concentrated $\mathrm{HCl}$ or $\mathrm{NaOH}$.

\subsection{Spectroscopy}

Fluorescence measurements of $\mathrm{CagFbFP}$ containing exclusively LC, RF, FMN or FAD were conducted using the Synergy H4 Hybrid Microplate Reader (BioTek, USA). Emission was measured between 470 and $700 \mathrm{~nm}$ (455 and $700 \mathrm{~nm}$ for LC) in increments of $1 \mathrm{~nm}$, with excitation fixed at $450 \mathrm{~nm}$ ( $435 \mathrm{~nm}$ for LC). Excitation was measured between 250 and $510 \mathrm{~nm}$ in increments of $1 \mathrm{~nm}$, the signal was detected at $530 \mathrm{~nm}$. Photobleaching, fluorescence quantum yield $\left(\Phi_{\mathrm{F}}\right)$ and extinction coefficient $(\varepsilon)$ were measured as described previously [30] except for the following details. For $\Phi_{\mathrm{F}}$ determinations, fluorescence of all samples was excited at $440 \mathrm{~nm}$. Extinction coefficient of $\mathrm{CagFbFP-LC}$ was measured using the extinction coefficient of free $\mathrm{LC}$ in aqueous solution at $385 \mathrm{~nm}\left(7600 \mathrm{M}^{-1} \mathrm{~cm}^{-1}\right)$ [45].

\subsection{Variation of expression conditions}

CagFbFP was expressed in E. coli strain C41 (DE3). Cells were cultured in shaking baffled flasks in LB medium containing $100 \mathrm{mg} \mathrm{l}^{-1}$ ampicillin. Protein expression was induced by the addition of isopropyl $\beta$-D-1thiogalactopyranoside (IPTG) when the culture reached an optical density of $0.6-0.7$ at $600 \mathrm{~nm}$. Two final IPTG concentrations were tested: 0.1 and $100 \mu \mathrm{M}$. Incubation continued for $4 \mathrm{~h}$ at $37{ }^{\circ} \mathrm{C}$. The cells were harvested by centrifugation at $4000 \mathrm{~g}$ for $10 \mathrm{~min}$. For photostability measurements, small fractions of the pellets were resuspended in the phosphate-buffered saline buffer and diluted to the optical density of 0.1 . For HPLC analysis of chromophore composition, the remaining cells were disrupted and the proteins were purified as described previously [30]. All the manipulations were performed under dim red light.

\subsection{Chromophore composition}

The protein-bound chromophore was released by denaturation in $7 \mathrm{M} \mathrm{GuHCl}$ dissolved in $50 \mathrm{mM}$ ammonium acetate, $\mathrm{pH}$ 6. The solution was incubated at $70{ }^{\circ} \mathrm{C}$ for $15 \mathrm{~min}$, then diluted to final concentration of $6 \mathrm{M} \mathrm{GuHCl}$ and centrifuged to remove denatured protein $(14000 \mathrm{rpm}, 20 \mathrm{~min})$. The supernatant was passed through Amicon Ultra- $0.5 \mathrm{~mL}$ filters (Merck (Millipore)) with pore size of $3 \mathrm{MWC}(13000 \mathrm{rpm}$, $60 \mathrm{~min}$ ) and directly used for high-performance liquid chromatography (HPLC).

For HPLC, we used the system from Shimadzu (LC10Ai), employing a XSelect HSS T3 XP Column, $100 \AA$, $2.5 \mu \mathrm{m}$, $4.6 \times 75 \mathrm{~mm}$; and from Thermo Scientific (UltiMate 3000 HPLC and UHPLC Systems), employing a Ascentis ${ }^{\circledR}$ Express C18 HPLC Column, $90 \AA$ \&, $2.7 \mu \mathrm{m}, 2.1 \times 150 \mathrm{~mm}$. $50 \mathrm{mM}$ ammonium acetate, $\mathrm{pH} 6$ (eluate $\mathrm{B}$ ) and $70 \%$ acetonitrile in B (eluate A) were used as solvents. Authentic LC, RF, FMN and FAD (Sigma-Aldrich) were used as reference compounds. During the separation, absorbance of the eluted samples at $263 \mathrm{~nm}$ was recorded. The following solvent gradient was applied: $t=0,10: 90 \mathrm{~A}: \mathrm{B}, t=7 \mathrm{~min}, 35: 65 \mathrm{~A}: \mathrm{B}$, $t=7.1 \mathrm{~min}, 40: 60 \mathrm{~A}: \mathrm{B}, t=9 \mathrm{~min}, 40: 60 \mathrm{~A}: \mathrm{B}, t=9.1 \mathrm{~min}$, 10:90 A:B, $t=11 \min , 10: 90 \mathrm{~A}: \mathrm{B}$. 


\subsection{Fluorescence microscopy}

Measurements were performed using LSM780 ELYRA PS.1 system (Carl Zeiss, Germany). E. coli cells were placed on a thin glass-bottom eight-well chambered coverslip (Ibidi, Germany), and fluorescence was excited by $488 \mathrm{~nm}$ laser in widefield using 100x $(\mathrm{NA}=1.46)$ oil immersion objective. Emission was detected with iXon997 camera (Andor, UK) in $512 \times 512$ px mode, using low gain and exposure time of $100 \mathrm{~ms}$. Background was masked and mean intensity across all cells was measured in each frame. Image processing was performed in FIJI [46].

\subsection{Determination of dissociation constants}

Dissociation constants were estimated by measuring the fluorescence of the protein upon controlled dilution. Free and bound flavin molecules have different emission spectra, which allowed us to decompose the spectra of mixtures of both into a sum of two spectra, and, thus, to estimate the concentration of each component. Titration curves were plotted for the fraction of the bound flavins versus the concentration of the free protein (apoprotein). We fitted the model to experimental data and estimated $K_{\mathrm{d}}$ and Hill-like coefficient using nonlinear least squares regression.

The protein-flavin complex was sequentially twofold diluted in buffer A $(300 \mathrm{mM} \mathrm{NaCl}, 50 \mathrm{mM}$ Tris-HCl, $\mathrm{pH}$ 8.0), to make a total of eight solutions. After each dilution, the solution was gently mixed using a pipette and incubated at $37{ }^{\circ} \mathrm{C}$ for $1 \mathrm{~h}$ to ensure complete equilibration [47]. Spectra were measured as described previously. For each protein-flavin pair, the experiment was performed three times to follow statistical errors. Free FAD is nearly nonfluorescent (23 times less bright than bound FAD as determined by authors), which results in large errors in the determination of concentrations. Therefore, six repeats were done for CagFbFP-FAD.

Supplementary Information The online version contains supplementary material available at https://doi.org/10.1007/s43630-021-00138-3.

Acknowledgements We are grateful to Mikhail Shevtsov and Tatiana Kotova (Moscow Institute of Physics and Technology) for help with HPLC experiments and Nina Malyar (Moscow Institute of Physics and Technology) for help with $\mathrm{pH}$ titration experiments. We are grateful to Thomas Drepper (Institute of Molecular Enzyme Technology, HHU Düsseldorf, FZ-Jülich) for sharing the data on thermal stability of FbFPs from thermophilic microorganisms and Esther Knieps-Grünhagen (Institute of Molecular Enzyme Technology, HHU Düsseldorf, FZ-Jülich) for help with protein purification. The work was supported by the Russian Science Foundation, grant number 21-64-00018.

\section{Declarations}

Conflict of interest The authors declare no conflict of interest.

\section{References}

1. Glantz, S. T., Carpenter, E. J., Melkonian, M., Gardner, K. H., Boyden, E. S., Wong, G.K.-S., \& Chow, B. Y. (2016). Functional and topological diversity of LOV domain photoreceptors. PNAS, 113(11), E1442-E1451. https://doi.org/10.1073/pnas.1509428113

2. Losi, A., \& Gärtner, W. (2017). Solving blue light riddles: New Lessons From Flavin-Binding LOV photoreceptors. Photochemistry and Photobiology, 93(1), 141-158. https://doi.org/10.1111/ php. 12674

3. Imaizumi, T., Tran, H. G., Swartz, T. E., Briggs, W. R., \& Kay, S. A. (2003). FKF1 is essential for photoperiodic-specific light signalling in Arabidopsis. Nature, 426, 302-306. https://doi.org/ 10.1038/nature02090

4. Liscum, E., \& Briggs, W. R. (1995). Mutations in the NPH1 locus of Arabidopsis disrupt the perception of phototropic stimuli. The Plant Cell, 7(4), 473-485. https://doi.org/10.1105/tpc.7.4.473

5. Huala, E., Oeller, P. W., Liscum, E., Han, I.-S., Larsen, E., \& Briggsll, W. R. (1997). Arabidopsis NPHl: A protein kinase with a putative redox-sensing domain. Science (80-), 278(5346), 21202123. https://doi.org/10.1126/science.278.5346.2120

6. Swartz, T. E., Tseng, T. S., Frederickson, M. A., Paris, G., Comerci, D. J., Rajashekara, G., Kim, J.-G., Mudgett, M. B., Splitter, G. A., Ugalde, R. A., Goldbaum, F. A., Briggs, W. R., \& Bogomolni, R. A. (2007). Blue-light-activated histidine kinases: two-component sensors in bacteria. Science (80-), 317(5841), 1090-1093. https://doi.org/10.1126/science.1144306

7. Ávila-Pérez, M., Hellingwerf, K. J., \& Kort, R. (2006). Blue light activates the sigma B-dependent stress response of Bacillus subtilis via YtvA. Journal of Bacteriology, 188(17), 6411-6414. https://doi.org/10.1128/JB.00716-06

8. Henry, J. T., \& Crosson, S. (2011). Ligand-binding PAS domains in a genomic, cellular, and structural context. Annual Review of Microbiology, 65, 261-286. https://doi.org/10.1146/annur ev-micro-121809-151631

9. Anderson, N. T., Weyant, K. B., \& Mukherjee, A. (2020). Characterization of flavin binding in oxygen-independent fluorescent reporters. AIChE Journal, 66(12), e17083. https://doi.org/10. 1002/aic. 17083

10. Dorn, M., Jurk, M., Wartenberg, A., Hahn, A., \& Schmieder, P. (2013). LOV Takes a pick: thermodynamic and structural aspects of the flavin-LOV-interaction of the blue-light sensitive photoreceptor YtvA from Bacillus subtilis. PLoS ONE, 8(11), e81268. https://doi.org/10.1371/journal.pone.0081268

11. Arinkin, V., Granzin, J., Röllen, K., Krauss, U., Jaeger, K.-E., Willbold, D., \& Batra-Safferling, R. (2017). Structure of a LOV protein in apo-state and implications for construction of LOVbased optical tools. Science and Reports, 7, 42971. https://doi. org/10.1038/srep42971

12. Mathes, T., Vogl, C., Stolz, J., \& Hegemann, P. (2009). In vivo generation of flavoproteins with modified cofactors. Journal of Molecular Biology, 385(5), 1511-1518. https://doi.org/10.1016/j. jmb.2008.11.001

13. Silva-Junior, M. R., Mansurova, M., Gärtner, W., \& Thiel, W. (2013). Photophysics of structurally modified flavin derivatives in the blue-light photoreceptor YtvA: A combined experimental and theoretical study. ChemBioChem, 14(13), 1648-1661. https:// doi.org/10.1002/cbic.201300217 
14. Kalvaitis, M. E., Johnson, L. A., Mart, R. J., Rizkallah, P., \& Allemann, R. K. (2019). A noncanonical chromophore reveals structural rearrangements of the light-oxygen-voltage domain upon photoactivation. Biochemistry, 58(22), 2608-2616. https:// doi.org/10.1021/acs.biochem.9b00255

15. Mansurova, M., Scheercousse, P., Simon, J., Kluth, M., \& Gärtner, W. (2011). Chromophore exchange in the blue light-sensitive photoreceptor YtvA from Bacillus subtilis. ChemBioChem, 12(4), 641-646. https://doi.org/10.1002/cbic.201000515

16. Mansurova, M., Simon, J., Salzmann, S., Marian, C. M., \& Gärtner, W. (2013). Spectroscopic and theoretical study on electronically modified chromophores in LOV domains: 8-bromo- and 8-trifluoromethyl-substituted flavins. ChemBioChem, 14(5), 645-654. https://doi.org/10.1002/cbic.201200670

17. Richert, S., Chen, J., Pompe, N., Radtke, V., Lllarionov, B., Fischer, M., Bacher, A., \& Weber, S. (2019). Influence of the cofactor structure on the photophysical processes initiating signal transduction in a phototropin-derived LOV domain. The Journal of Chemical Physics. https://doi.org/10.1063/1.5131856

18. Tyagi, A., Penzkofer, A., Mathes, T., \& Hegemann, P. (2010). Photophysical characterisation and photo-cycle dynamics of LOV1his domain of phototropin from Chlamydomonas reinhardtii with roseoflavin monophosphate cofactor. Journal of Photochemistry and Photobiology B, 101(1), 76-88. https://doi.org/10.1016/j. jphotobiol.2010.06.014

19. Pudasaini, A., El-Arab, K. K., \& Zoltowski, B. D. (2015). LOVbased optogenetic devices: Light-driven modules to impart photoregulated control of cellular signaling. Frontiers in Molecular Biosciences, 2, 1-15. https://doi.org/10.3389/fmolb.2015.00018

20. Losi, A., Gardner, K. H., \& Möglich, A. (2018). Blue-light receptors for optogenetics. Chemical Reviews, 118(21), 10659-10709. https://doi.org/10.1021/acs.chemrev.8b00163

21. Chia, H. E., Marsh, E. N. G., \& Biteen, J. S. (2019). Extending fluorescence microscopy into anaerobic environments. Current Opinion in Chemical Biology, 51, 98-104. https://doi.org/10. 1016/j.cbpa.2019.05.008

22. Mukherjee, A., \& Schroeder, C. M. (2015). Flavin-based fluorescent proteins: emerging paradigms in biological imaging. Current Opinion in Biotechnology, 31, 16-23. https://doi.org/10.1016/j. copbio.2014.07.010

23. Chapman, S., Faulkner, C., Kaiserli, E., Garcia-Mata, C., Savenkov, E. I., Roberts, A. G., Oparka, K. J., \& Christie, J. M. (2008). The photoreversible fluorescent protein ILOV outperforms GFP as a reporter of plant virus infection. PNAS, 105(50), 20038-20043. https://doi.org/10.1073/pnas.0807551105

24. Drepper, T., Eggert, T., Circolone, F., Heck, A., Krauß, U., Guterl, J.-K., Wendorff, M., Losi, A., Gärtner, W., \& Jaeger, K.-E. (2007). Reporter proteins for in vivo fluorescence without oxygen. Nature Biotechnology, 25(4), 443-445. https://doi.org/10.1038/nbt1293

25. Ozbakir, H. F., Anderson, N. T., Fan, K.-C., \& Mukherjee, A. (2020). Beyond the green fluorescent protein: Biomolecular reporters for anaerobic and deep-tissue imaging. Bioconjugate Chemistry, 31(2), 293-302. https://doi.org/10.1021/acs.bioco njchem.9b00688

26. Daniel, R. M., Cowan, D. A., Morgan, H. W., \& Curran, M. P. (1982). A correlation between protein thermostability and resistance to proteolysis. The Biochemical Journal, 207(3), 641-644. https://doi.org/10.1042/bj2070641

27. Parsell, D. A., \& Sauer, R. T. (1989). The structural stability of a protein is an important determinant of its proteolytic susceptibility in Escherichia coli. Journal of Biological Chemistry, 264(13), 7590-7595. https://doi.org/10.1016/s0021-9258(18)83275-6

28. Bloom, J. D., Labthavikul, S. T., Otey, C. R., \& Arnold, F. H. (2006). Protein stability promotes evolvability. Proceedings of the National academy of Sciences of the United States of America, 103(15), 5869-5874. https://doi.org/10.1073/pnas.0510098103
29. Wingen, M., Jaeger, K.-E., Gensch, T., \& Drepper, T. (2017). Novel thermostable flavin-binding fluorescent proteins from thermophilic organisms. Photochemistry and Photobiology, 93(3), 849-856. https://doi.org/10.1111/php.12740

30. Nazarenko, V. V., Remeeva, A., Yudenko, A., Kovalev, K., Dubenko, A., Goncharov, I. M., Kuzmichev, P., Rogachev, A. V., Buslaev, P., Borshchevskiy, V., Mishin, A., Dhoke, G. V., Schwaneberg, U., Davari, M. D., Jaeger, K.-E., Krauss, U., Gordeliy, V., \& Gushchin, I. (2019). A Thermostable flavin-based fluorescent protein from: Chloroflexus Aggregans: a framework for ultra-high resolution structural studies. Photochemical and Photobiological Sciences, 18(7), 1793-1805. https://doi.org/10. 1039/c9pp00067d

31. Remeeva, A., Nazarenko, V. V., Goncharov, I. M., Yudenko, A., Smolentseva, A., Semenov, O., Kovalev, K., Gülbahar, C., Schwaneberg, U., Davari, M. D., Gordeliy, V., \& Gushchin, I. (2020). Effects of proline substitutions on the thermostable lov domain from Chloroflexus Aggregans. Crystals, 10(4), 256. https://doi.org/10.3390/cryst10040256

32. Remeeva, A., Nazarenko, V. V., Kovalev, K., Goncharov, I. M., Yudenko, A., Astashkin, R., Gordeliy, V., \& Gushchin, I. (2021). Insights into the mechanisms of light-oxygen-voltage domain color tuning from a set of high-resolution X-ray structures. Proteins Structure Function and Bioinformatics. https://doi.org/10. 1002/prot.26078

33. Röllen, K., Granzin, J., Remeeva, A., Davari, M. D., Gensch, T., Nazarenko, V. V., Kovalev, K., Bogorodskiy, A., Borshchevskiy, V., Hemmer, S., Schwaneberg, U., Gordeliy, V., Jaeger, K. E., Batra-Safferling, R., Gushchin, I., \& Krauss, U. (2021). The molecular basis of spectral tuning in blue- and red-shifted flavinbinding fluorescent proteins. Journal of Biological Chemistry, 296, 100662. https://doi.org/10.1016/j.jbc.2021.100662

34. Yudenko, A., Smolentseva, A., Maslov, I., Semenov, O., Goncharov, I. M., Nazarenko, V. V., Maliar, N. L., Borshchevskiy, V., Gordeliy, V., Remeeva, A., \& Gushchin, I. (2021). Rational design of a split flavin-based fluorescent reporter. ACS Synthetic Biology, 10(1), 72-83. https://doi.org/10.1021/acssynbio.0c00454

35. Holzer, W., Shirdel, J., Zirak, P., Penzkofer, A., Hegemann, P., Deutzmann, R., \& Hochmuth, E. (2005). Photo-induced degradation of some flavins in aqueous solution. Chemical Physics, 308(1-2), 69-78. https://doi.org/10.1016/j.chemphys.2004.08.006

36. Torra, J., Lafaye, C., Signor, L., Aumonier, S., Flors, C., Shu, X., Nonell, S., Gotthard, G., \& Royant, A. (2019). Tailing MiniSOG: Structural bases of the complex photophysics of a flavin-binding singlet oxygen photosensitizing protein. Science and Reports, 9(1), 1-10. https://doi.org/10.1038/s41598-019-38955-3

37. Kopka, B., Magerl, K., Savitsky, A., Davari, M. D., Röllen, K., Bocola, M., Dick, B., Schwaneberg, U., Jaeger, K. E., \& Krauss, U. (2017). Electron transfer pathways in a light, oxygen, voltage (LOV) protein devoid of the photoactive cysteine. Science and Reports, 7(1), 1-16. https://doi.org/10.1038/s41598-017-13420-1

38. Schwerdtfeger, C., \& Linden, H. (2003). VIVID is a flavoprotein and serves as a fungal blue light photoreceptor for photoadaptation. EMBO Journal, 22(18), 4846-4855. https://doi.org/10.1093/ emboj/cdg 451

39. Song, X., Wang, Y., Shu, Z., Hong, J., Li, T., \& Yao, L. (2013). Engineering a more thermostable blue light photo receptor Bacillus subtilis YtvA LOV Domain By A Computer Aided Rational Design Method. PLoS Computational Biology, 9(7), e1003129. https://doi.org/10.1371/journal.pcbi.1003129

40. Higgins, S. A., Ouonkap, S. V. Y., \& Savage, D. F. (2017). Rapid and programmable protein mutagenesis using plasmid recombineering. ACS Synthetic Biology, 6(10), 1825-1833. https://doi. org/10.1021/acssynbio.7b00112

41 Hanada, S., Hiraishi, A., Shimada, K., \& Matsuura, K. (1995). Chloroflexus Aggregans Sp. Nov., a filamentous phototrophic 
bacterium which forms dense cell aggregates by active gliding movement. International Journal of Systematic Bacteriology., 45(4), 676-681. https://doi.org/10.1099/00207713-45-4-676

42. Petrenčáková, M., Varhač, R., Kožár, T., Nemergut, M., Jancura, D., Schwer, M.-S., \& Sedlák, E. (2020). Conformational properties of LOV2 domain and its C450A variant within Broad PH region. Biophysical Chemistry, 259, 106337. https://doi.org/10. 1016/j.bpc.2020.106337

43 Zoltowski, B. D., Schwerdtfeger, C., Widom, J., Loros, J. J., Bilwes, A. M., Dunlap, J. C., \& Crane, B. R. (2007). Conformational switching in the fungal light sensor vivid. Science (80-), 316(5827), 1054-1057. https://doi.org/10.1126/science.1137128

44 He, Q., Cheng, P., Yang, Y., Wang, L., Gardner, K. H., \& Liu, Y. (2002). White collar-1, a DNA binding transcription factor and a light sensor. Science (80-), 297(5582), 840-843. https://doi.org/ $10.1126 /$ science. 1072795
45. Sikorska, E., Khmelinskii, I. V., Prukała, W., Williams, S. L., Patel, M., Worrall, D. R., Bourdelande, J. L., Koput, J., \& Sikorski, M. (2004). Spectroscopy and photophysics of lumiflavins and lumichromes. Journal of Physical Chemistry, 108(9), 1501-1508. https://doi.org/10.1021/jp037048u

46. Schindelin, J., Arganda-Carreras, I., Frise, E., Kaynig, V., Longair, M., Pietzsch, T., Preibisch, S., Rueden, C., Saalfeld, S., Schmid, B., Tinevez, J. Y., White, D. J., Hartenstein, V., Eliceiri, K., Tomancak, P., \& Cardona, A. (2012). Fiji: An open-source platform for biological-image analysis. Nature Methods, 9(7), 676-682. https://doi.org/10.1038/nmeth.2019

47. Jarmoskaite, I., Alsadhan, I., Vaidyanathan, P. P., \& Herschlag, D. (2020). How to measure and evaluate binding affinities. eLife, 9, e57264. https://doi.org/10.7554/ELIFE.57264

\section{Authors and Affiliations}

\section{Anastasia Smolentseva ${ }^{1} \cdot$ Ivan M. Goncharov ${ }^{1} \cdot$ Anna Yudenko $^{1} \cdot$ Andrey Bogorodskiy $^{1} \cdot$ Oleg Semenov $^{1}$. Vera V. Nazarenko ${ }^{1}$. Valentin Borshchevskiy ${ }^{1,6}$ - Alexander V. Fonin ${ }^{2}$ - Alina Remeeva ${ }^{1}$ - Karl-Erich Jaeger ${ }^{3,4}$. Ulrich Krauss $^{3,4} \cdot$ Valentin Gordeliy ${ }^{1,5,6} \cdot$ Ivan Gushchin $^{1}$ (1)}

1 Research Center for Molecular Mechanisms of Aging and Age-Related Diseases, Moscow Institute of Physics and Technology, Dolgoprudny, Russia

2 Institute of Cytology, Russian Academy of Sciences, 194064 Saint Petersburg, Russia

3 Institute of Molecular Enzyme Technology, Heinrich Heine University Düsseldorf, Forschungszentrum Jülich, Jülich, Germany
4 Institute of Bio- and Geosciences IBG-1: Biotechnology, Forschungszentrum Jülich GmbH, Jülich, Germany

5 Institut de Biologie Structurale J.-P. Ebel, Université Grenoble Alpes-CEA-CNRS, 38000 Grenoble, France

6 Institute of Biological Information Processing IBI-7: Structural Biochemistry, Forschungszentrum Jülich, 52428 Jülich, Germany 